\title{
Predictors of complementary feeding in infants aged 6 to 18 months: An application of Health Belief Model
}

\author{
*Amin Mirzaei ${ }^{1}$, Fateme Pur Esmaeili ${ }^{1}$, Mohsen Jalilian ${ }^{1}$
}

Sri Lanka Journal of Child Health, 2020; 49(1): 48-53

\begin{abstract}
Introduction: Complementary feeding plays a vital role in growth and development of children and prevention of malnutrition.
\end{abstract}

Objective: To determine the predictors of complementary feeding in 6 to 18 -month-old infants and young children based on the Health Belief Model (HBM).

Method: This cross-sectional study was performed on 270 mothers of children aged 6 to 18 months who were randomly selected from those referred to six health centres in Andimeshk city, Iran. Data were gathered using a 53-item questionnaire based on the HBM and were analysed by SPSS statistical software, descriptive statistics, Pearson correlation and multiple regression tests.

Results: Mean age of the mothers was $29.8 \pm 5.08$ years and most of them were homemakers $(88.5 \%)$ and had an under-diploma education $(62.2 \%)$. The HBM constructs predicted a total of $28.9 \%$ of the variance of mothers' behaviour in relation to complementary feeding in children. Perceived selfefficacy $(p=0.001)$ and perceived barriers $(p=$ $0.011)$ significantly predicted the behaviour.

Conclusions: Perceived barriers and perceived self-efficacy are the most important determinants of mothers' behaviour in relation to complementary feeding in children.

DOI: http://dx.doi.org/10.4038/sljch.v49i1.8898

(Keywords: Complementary feeding, child, Health Belief Model)

${ }_{1}^{1}$ Ilam University of Medical Sciences, Islamic
Republic of Iran
${ }^{*}$ Correspondence: mirzaei.amin62@gmail.com

(D) https://orcid.org/0000-0001-9625-5486

(Received on 25 June 2019: Accepted after revision on 19 July 2019)

The authors declare that there are no conflicts of interest

Personal funding was used for the project.

Open Access Article published under the Creative

Commons Attribution CC-BY (c) (i) License

\section{Introduction}

Childhood nutrition plays a significant role in growth as well as physical, psychological and social performance of a person in the future ${ }^{1}$. Previous studies show that the first two years of life are the most important period for growth and development of infants ${ }^{2}$. Infants aged less than two years old are very vulnerable to malnutrition due to their nutritional needs for growth ${ }^{3-5}$. Since the high rate of growth during infancy is accompanied by certain changes in the function and composition of organs, a defect in providing adequate food in this period can have destructive effects on development in addition to growth disorders $\mathrm{s}^{3-6}$. The destructive effects of malnutrition include immune disorders, respiratory disorders, gastrointestinal infections, disruption of central nervous system growth and consequently, reduced mental abilities ${ }^{7,8}$. Malnutrition is the direct and indirect reason for half of the 10.9 million deaths of kids under the age of 5 in the world and more than two thirds of these deaths are usually associated with poor nutrition in the first two years of life 9 . In Iran, kid's malnutrition is considered as a major health issue and several studies have reported the prevalence of underweight in Iranian kids ${ }^{3,6,10}$.

In many developing countries, including Iran, infants are exclusively breast-fed until the age of 6 months ${ }^{6}$. After 6 months of age, breastfeeding cannot solely meet the nutritional needs of infants. According to WHO and UNICEF recommendations, complementary feeding (CF) of kids should be started since the age of 6 months ${ }^{11,12}$. CF should have good quality and quantity to provide the energy, protein and nutrients needed for growth and development of infants $^{12}$.

Mothers, as the closest persons to kids, play a major role in health care, especially in their nutrition. Mothers' behaviours in relation to kid nutrition can be greatly influenced by their knowledge, attitudes and beliefs ${ }^{5,13}$. According to the Health Belief Model (HBM), whatever mothers are susceptible to the risks of malnutrition in their kids and its short-term and long-term complications, they have a greater incentive to take preventive behaviours. On the other hand, understanding the benefits of preventing malnutrition and trying to eliminate barriers to 
preventative behaviour can increase the likelihood of doing these behaviours. In addition, it is necessary for mother to be efficient enough and utilize from reliable guidelines in order to perform healthy behaviours such as $\mathrm{CF}$ of $\mathrm{kids}^{5,14}$. It is essential to accurately conduct educational needs assessment before planning and implementation of educational interventions to improve the CF of kids so that implementation of educational programs will also be cost-effective and cost-beneficial.

\section{Objectives}

To determine the predictors of CF in Infants aged 6 to 18 months based on the Health Belief Model.

\section{Method}

Study design and sampling: Two hundred and seventy mothers with infants aged from 6 to 18 months participated in the present cross-sectional study. The samples were randomly selected in two stages among individuals referred to health centres (HCs) of Andimeshk city, Iran. For this purpose, six $\mathrm{HCs}$ were randomly selected from $17 \mathrm{HCs}$. Then, a list of 50 infants, aged from 6 to 18 months, was randomly selected. Then, the names and addresses of mothers of these infants were extracted and recorded by referring to the family health files. The objectives of present study were described to selected mothers and they were invited to the study by phone. Finally, mothers participated in present study by referring to $\mathrm{HC}$ and completing the written consent form.

The inclusion criteria for mothers were having an infant aged 5 to 18 months old, a minimum reading and writing literacy, and a written consent for participation in the study. The exclusion criteria included kids with severe congenital anomalies or special dietary restrictions. Also, kids whose mothers had died, or were not under the care of their mother, were excluded.

Measurements: Data were gathered using a questionnaire in three parts. The first part of questionnaire with 10 items measured the demographic information. The second part of questionnaire included 34 items based on HBM. Perceived susceptibility, perceived severity and perceived benefits consisted of 5 items. Also, 8 items were related to perceived barriers and 9 items to perceived self-efficacy. Answers of this part of questionnaire were scored using a 5-point Likert scale (from $5=$ "strongly agree" to $1=$ "strongly disagree").The cues to action were also measured using two items. The third part of questionnaire with 9 items was used to evaluate the behaviour of mothers in relation to $\mathrm{CF}$ of infants. The validity of questionnaire was qualitatively investigated using the panel of 5 health education and health promotion experts about simplicity and clarity, proportionality, ambiguity, necessity and scoring of items and the required corrections were made on the questionnaire based on their opinions. The reliability (internal consistency) of questionnaire was also confirmed using Cronbach's alpha, which obtained amounts that are presented in Table 2. Present study was approved by Ethics Committee of Ilam University of Medical Sciences.

Data analysis: Data were analysed by SPSS software using descriptive statistics, bivariate correlations and multiple logistic regression (Enter method) tests.

\section{Results}

270 mothers aged 19 to 47 years old with a mean age of $29.8 \pm 5.08$ years old participated in the present study. Most of study subjects were housewives $(88.5 \%)$ with under-diploma educational level $(62.2 \%)$. Also, the mean age of infants was $11.69 \pm 4.13$ months with age range of 5 to 18 months and most of them (44.4\%) were the first child of the family (Table 1).

\section{Table 1}

Socio-demographic characteristics of study participants

\begin{tabular}{|l|c|}
\hline \multicolumn{1}{|c|}{ Characteristic } & Number (\%) \\
\hline Child gender & $136(50.4)$ \\
Fale & $134(49.6)$ \\
\hline Child birth rank & $120(44.4)$ \\
First & $118(43.7)$ \\
Second & $32(11.9)$ \\
Third or higher & \\
\hline Educational level & $48(17.8)$ \\
Elementary & $120(44.4)$ \\
Under diploma & $102(37.8)$ \\
Diploma or higher & \\
\hline Occupational situation & $239(88,5)$ \\
Householder & $21(07.8)$ \\
Employee & $10903.7)$ \\
Self-employment & \\
\hline Socioeconomic status & $43(15.9)$ \\
Low & $185(68.7)$ \\
Intermediate & $42(15.6)$ \\
High &
\end{tabular}

The mean score and standard deviation of HBM constructs as well as the behaviour related to $\mathrm{CF}$ of infants are presented in Table 2.

As shown in Table 3, all constructs of HBM had a significant correlation with behaviour. However, perceived self-efficacy $(\mathrm{p}<0.001, \mathrm{r}=0.524)$ and perceived barriers $(r=-0.263, p<0.001)$ had the strongest correlation with behaviour. 
Table 2: Means, standard deviations, number of items, obtainable score range and internal consistency of HBM constructs and complementary feeding behaviours $(n=270)$

\begin{tabular}{|l|c|c|c|c|}
\hline \multicolumn{1}{|c|}{ Variable } & Mean (SD) & No. of items & Obtainable score range & Internal consistency* \\
\hline Perceived susceptibility & $23.15(2.31)$ & 5 & $5-25$ & 0.82 \\
\hline Perceived severity & $21.76(2.97)$ & 5 & $5-25$ & 0.81 \\
\hline Perceived benefits & $23.22(2.46)$ & 5 & $5-25$ & 0.93 \\
\hline Perceived barriers & $19.68(6.59)$ & 8 & $8-40$ & 0.61 \\
\hline Self-efficacy & $38.94(5.64)$ & 9 & $9-45$ & 0.88 \\
\hline Behaviour & $33.92(7.04)$ & 9 & $9-45$ & 0.91 \\
\hline
\end{tabular}

${ }^{*}$ Cronbach's alpha, SD: standard deviation

Table 3: Inter-correlations of HBM constructs and complementary feeding behaviours ( $n=270)$

\begin{tabular}{|l|c|c|c|c|c|c|}
\hline \multicolumn{1}{|c|}{ Variable } & $\mathbf{1}$ & $\mathbf{2}$ & $\mathbf{3}$ & $\mathbf{4}$ & $\mathbf{5}$ & $\mathbf{6}$ \\
\hline Perceived susceptibility & 1 & & & & & \\
\hline Perceived severity & $0.564^{*}$ & 1 & & & & \\
\hline Perceived benefits & $0.392^{*}$ & $.0441^{*}$ & 1 & & & \\
\hline Perceived barriers & -0.110 & -0.062 & -0.104 & 1 & & \\
\hline Self-efficacy & $0.276^{*}$ & $0.281^{*}$ & $0.298^{*}$ & $-0.244^{*}$ & 1 & \\
\hline Behaviour & $0.184^{*}$ & $0.197^{*}$ & $0.191^{*}$ & $-0.263^{*}$ & $0.524^{*}$ & 1 \\
\hline
\end{tabular}

* Correlation is significant at the 0.01 level (2-tailed)

According to the multiple regression analysis, constructs of HBM totally predicted $28.9 \%$ of variance of mothers' behaviour in relation to $\mathrm{CF}$ in infants. Only two constructs of perceived selfefficacy and perceived barriers could significantly predict the behaviour (Table 4).

Table 4: Multiple regression analysis: HBM variables predicting complementary feeding behaviours $(n=270)$

\begin{tabular}{|l|c|c|c|c|c|c|c|}
\hline \multicolumn{1}{|c|}{ Variable } & B & Std. error & $\beta$ & $\mathrm{R}$ & $\mathrm{R}^{2}$ & $\mathrm{~F}$ & sig \\
\hline Perceived susceptibility & 0.011 & 0.202 & 0.004 & & & .957 \\
\hline Perceived severity & 0.094 & 0.159 & 0.039 & & & & .554 \\
\hline Perceived benefits & 0.074 & 0.175 & 0.026 & & & & .671 \\
\hline Perceived barriers & -0.151 & 0.058 & -0.142 & & & & $.011^{*}$ \\
\hline Self-efficacy & 0.580 & 0.072 & 0.465 & 0.538 & 0.298 & 20.64 & $.001^{*}$ \\
\hline
\end{tabular}

* Significant at the 0.01 level (2-tailed), Dependent variable: Complementary feeding behaviours

According to the findings of the present study, $82.6 \%$ of participants reported that they have received information about their infants' $\mathrm{CF}$ from at least one source. Health care staff played the major role in directing mothers about $\mathrm{CF}$ with $65.9 \%$. Print media such as books and magazines with $14.4 \%$ had the lowest share in this regard (Figure 1).

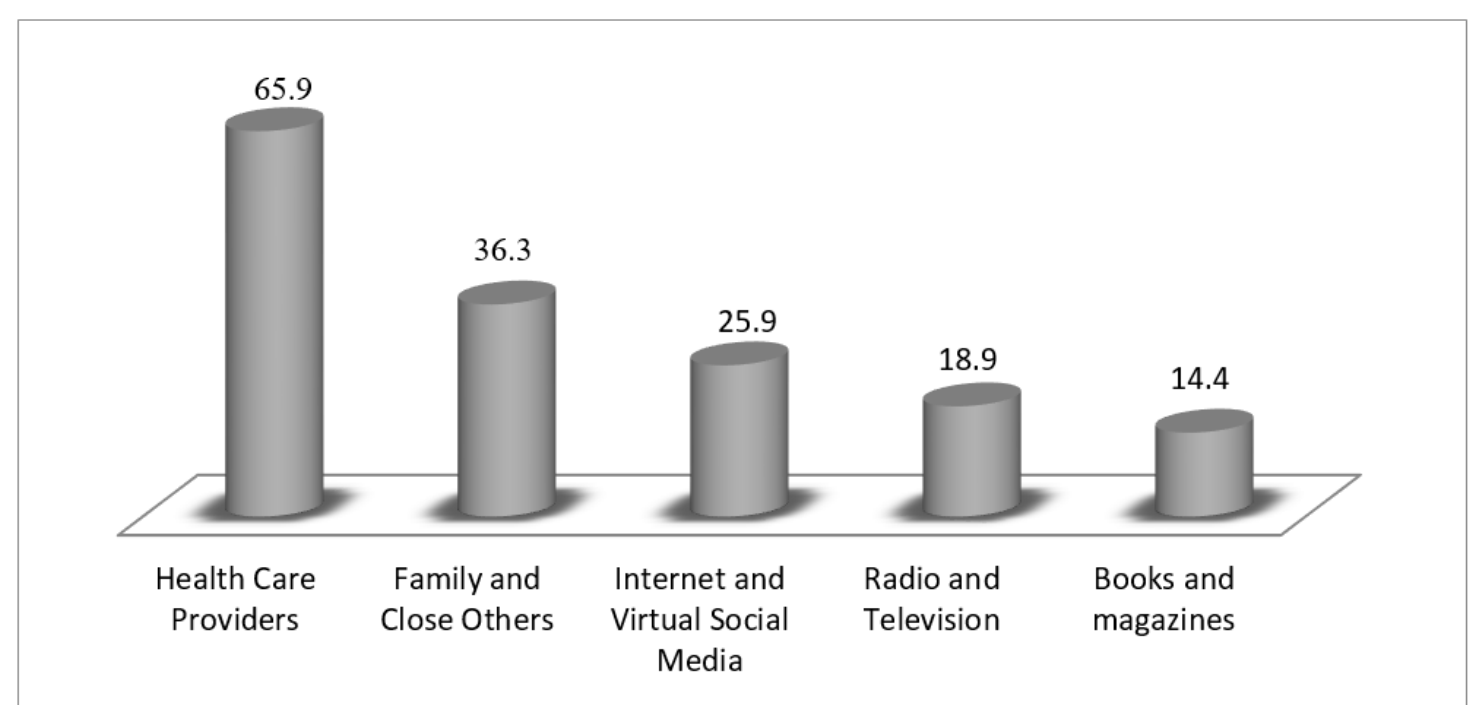

Figure 1: Relative frequency (\%) of external cues to action in relation to complementary feeding in study participants 


\section{Discussion}

The purpose of the present study was to determine the predictors of CF in infants aged 6 to 18 months based on HBM. According to the study results, the HBM constructs predicted a total of $29 \%$ of the variance of mothers' behaviour in relation to $\mathrm{CF}$. Although the overall regression model was significant, only perceived self-efficacy and perceived barriers significantly predicted the behaviours. The findings indicated that mothers are adequately susceptible to CF of infants and have perceived the serious side effects of malnutrition. Also, they had a proper perception about benefits of their kids' CF. Other studies have reported similar results. In a study conducted by Lindsay et al (2008), mothers participating in the study properly perceived the benefits of CF but they reported many behavioural barriers such as insufficient access to healthy food and high cost of supplements for $\mathrm{kids}^{15}$. In a study conducted by Tariku et al (2015), mothers also highly perceived the threat of malnutrition for kids. However, they had a weak practice due to perceiving barriers such as lack of knowledge and skills about preparation of $\mathrm{CF}$, the cost of providing $\mathrm{CF}$ and lack of $\mathrm{CF}$ acceptance by kids $^{5}$.

In the present study, the perceived barriers of mothers included inadequate support of family members for providing $\mathrm{CF}$, unnecessary interference of others in providing $\mathrm{CF}$, lack of knowledge and skills about preparation of CF and lack of infant's desire to CF. The findings indicate that perceiving health threat by mothers and even the high expectations and values of outcome of mothers' behaviour cannot solely lead to their desirable practice in relation to $\mathrm{CF}^{5,16}$ and it is necessary to resolve the perceived behavioural barriers by mothers. On the other hand, a positive and significant correlation between perceived barriers and self-efficacy indicates the necessity of improving mothers' self-efficacy to decrease these behavioural barriers ${ }^{5,17}$. To improve the selfefficacy, the knowledge of mothers about principles of CF for infants and food diversification should be firstly improved in addition to following CF model provided by Ministry of Health ${ }^{18}$ and then, mothers should acquire adequate skills to prepare and maintain $\mathrm{CF}$. In addition, the selfefficacy of mothers is significantly affected by supports of family and friends ${ }^{6}$. Family plays a major and the most important role in mental and emotional support of mother and is a good action cue for mothers to decide and behave in kid's nutrition $^{6}$. Lack of adequate family support can have a negative effect on self-efficacy of mothers as well as their performance in relation to $\mathrm{CF}$.

According to the study results, health care staff played the major role in educating and guidance of mothers for $\mathrm{CF}$ in infants. Other studies confirm this finding ${ }^{19-22}$. However, much education provided by health care staff for mothers in relation to CF have not had enough effectiveness ${ }^{16,18}$ and cannot bridge the gap between the knowledge and behaviour of mothers about CF of infants ${ }^{16-19}$. Hence, educational interventions in this area should be based on accurate educational need assessment and focusing on the most important determinants of behaviour. The findings of several studies ${ }^{5,17}$ indicated the effectiveness of HBM-based interventions on the behaviour of mothers in relation to $\mathrm{CF}$ of infants. The results of present study and other similar studies can be considered as a suitable framework for implementing educational interventions in the field of CF of kids. However, it seems necessary to conduct further studies using HBM and other behaviour change theories to recognize the behavioural determinants of kids' CF.

\section{Conclusions}

The results of present study indicated that only two constructs of perceived barriers and self-efficacy significantly predicted the behaviour despite a significant correlation between all constructs of HBM and mothers' behaviour in relation to $\mathrm{CF}$ of infants.

\section{Acknowledgments}

The authors thank all mothers for participation in present study as well as thanks for staff of health care centres for their help.

\section{References}

1. Asadi S, Jafari F. The effect of complementary feeding training on rural mothers' awareness, attitude and practice in villages of Abhar Health Care Coverage Network. Journal of Zanjan University of Medical Sciences and Health Services 2014; 23(96):122-30.

2. Babazade T, Moradi M, Zibaee N. Impact of educational intervention on mothers empowerment about proper nutrition among infants under 2 years of age covered by health homes of district 18 of Tehran municipality. Iranian Journal of Health Education and Health Promotion 2014; 2(3):242-50.

3. Heird WC. The feeding of infants and children. In: Behrman RE. Kehgram RM, Jenson HN. The Textbook of Pediatrics. 17th ed. Philadelphia: W.B. Saunders Company; 2004. p 157-67. 
4. Panahande Z, Dousdar Sanaye M. Infants' complementary food pattern and mothers' knowledge in rural areas in Rasht city. Gilan University of Medical Sciences 2008; 18(59):9-15.

5. Tariku B, Whiting SJ, Mulualem D, Singh P. Application of the health belief model to teach complementary feeding messages in Ethiopia. Ecology of Food and Nutrition 2015; 54 (5):572-82. https://doi.org/10.1080/03670244.2015.10 49344

PMid: 26075935

6. Shams N, Mostafavi F, Hassanzadeh A. Determinants of complementary feeding practices among mothers of 6-24 months failure to thrive children based on behavioural analysis phase of PRECEDE model, Tehran. Journal of Education and Health Promotion 2016; 5: 24. https://doi.org/10.4103/2277-9531.184565 PMid: 27500177 PMCid: PMC4960768

7. Demissie S, Worku A. Magnitude and factors associated with malnutrition in children 6-59 months of age in pastoral community of Dollo Ado District, Somali region, Ethiopia. Science Journal of Public Health 2013; 1: 175-83. https://doi.org/10.11648/j.sjph.20130104.1 2

8. Black RE, Allen LH, Bhutta ZA, Caulfield LE, De Onis M, Ezzati M, et al. Maternal and child undernutrition: global and regional exposures and health consequences. Lancet 2008; 371:243-60. https://doi.org/10.1016/S01406736(07)616 90-0

9. Golshiri P, Sharifirad Gh, Baghernezhad F. Comparison of two methods of education (lecture and self-learning) on knowledge and practice of mothers with under 3 year old children about growth monitoring and nutritional development stages. Iranian Journal of Medical Education 2010; 10(5):927-36.

10. Abedzadeh Zavareh MS, Hasani M, Darabi M, Mirzaei A, Khorshidi A, Saeidi $\mathrm{A}$, et al. Growth indicators and nutritional supplement evaluation in 6-12 months year old children's: A perspective From Ilam. Electronic Journal of General Medicine 2018; 15 (3). https://doi.org/10.29333/ejgm/85494
11. Khazaei T, Amoozeshi Z, Ahmadi S, Safamanesh B, Mahmoodi H. The effect of education on mother's knowledge and practice about supplementary nutrition for children under one year. Birjand University of Medical Sciences 2006; 3(3):10-15.

12. Kamran A, Sharifirad G, Nasiri K, Soleymanifard P, Savadpour M, Akbar Haghighat M. Determinants of complementary feeding practices among children aged 6-23: a community based study. International Journal of Pediatrics 2017; 5(3):4551-60.

13. Mirzaei A, Nourmoradi H, Zavareh MS, Jalilian M, Mansourian M, Mazloomi S, et $a l$. Food dafety knowledge and practices of male adolescents in West of Iran. Macedonian Journal of Medical Sciences 2018; 6(5):908.

https://doi.org/10.3889/oamjms.2018.175

14. Mazloomy S, Mirzaei A, Afkhami Ardakani M, Baghiani Moghadam M, Fallahzadeh $\mathrm{H}$. The role of health beliefs in preventive behaviours of individuals at high-risk of type 2 diabetes mellitus. SSU Journals 2010; 18(1):24-31.

15. Lindsay AC, Machado MT, Sussner KM, Hardwick CK, Peterson KE. Infantfeeding practices and beliefs about complementary feeding among lowincome Brazilian mothers: a qualitative study. Food and Nutrition Bulletin 2008; 29(1):15-24.

https://doi.org/10.1177/156482650802900 102

PMid: 18510201

16. Salarkia N, Amini M, Eslami Amirabadi M, Dadkhah M, Zowghi T, Heidari H, et al. Mothers' views and beliefs about the role of complementary feeding in children under the age of two in Damavand: a qualitative study. Arak Medical University Journal 2010; 13(2): 63-74.

17. Mulualem D, Henry CJ, Berhanu G, Whiting SJ. The effectiveness of nutrition education: Applying the Health Belief Model in child-feeding practices to use pulses for complementary feeding in Southern Ethiopia. Ecology of Food and Nutrition 2016; 55(3):308-23. 
https://doi.org/10.1080/03670244.2016.11

61617

PMid: 27065308

18. Sayari A, Parsay S, Shekholeslam R, Kolahdooz F, Farivar K, Samadpour K, et al. Nutrition requirements in children up to 6 years. In: Kolahdooz F, Zanjani NE, Kani GS. Improving Growth and Nutrition of Children. 3st ed. Tehran: Ministry of Health \& Medical Education \& UNICEF; 2004. p. 17-8.

19. Joukar F, Ezbarami ZT, Yegane MR. Situation of supplementary feeding in 6-12 month old children in Ilam. Hayat J (Fac Nurs Midwifery Tehran Univ Med Sci) 2008; 14: 61-8.

20. Dorypour F, Majidy F, Modaressy MR. The study of mothers' knowledge of children beyond 2 years about complementary nutrition in health care centre of Fassa in 2003. J Boghrat, Fassa Univ Med Sci. 2004; 2(3): 46-54.

21. Fesharakinia A, Sharifzadeh GR \& Habbiby M. Evaluation of infants' complementary nutrition pattern and some of its associated factors in Birjand. Journal of Birijand University of Medical Sciences 2009; 16(3):40-6.

22. Khoshnevisasl $\mathrm{P}$, Sadeghzadeh $\mathrm{M}$, Mazloomzadeh S, Koosha A, Dariabari S. Maternal knowledge about nutritional status of 6-12 Month old infants in the community oriented medical education of Zanjan Univ Med Sci J 2010; 18:61-9. 